\title{
SPOTLIGHT ON AGE-DIVERSITY CLIMATE: THE IMPACT OF AGE-INCLUSIVE HR PRACTICES ON FIRM-LEVEL OUTCOMES
}

\author{
STEPHAN A. BOEHM \\ University of St. Gallen \\ FLORIAN KUNZE \\ University of St. Gallen \\ HEIKE BRUCH \\ University of St. Gallen
}

\begin{abstract}
This study investigates the emergence and the performance effects of an age-diversity climate at the organizational level of analysis. Building upon Kopelman and colleagues' (Kopelman, Brief, \& Guzzo, 1990) climate model of firm productivity as well as Cox's (1994) interactional model of cultural diversity, we hypothesize a positive influence of ageinclusive HR practices on the development of an organization-wide agediversity climate, which in turn should be directly related to collective perceptions of social exchange and indirectly to firm performance and employees' collective turnover intentions. The assumed relationships are tested in a sample of 93 German small and medium-sized companies with 14,260 employees participating. To circumvent common source problems, information for the various constructs was gathered from 6 different sources. To test our assumed relationships, we applied structural equation modeling and executed bootstrapping procedures to test the significance of the indirect effects. We received support for all assumed relationships. The paper concludes with practical recommendations on how to establish and make use of a positive age-diversity climate.
\end{abstract}

Due to the combined effect of low fertility rates, rising life expectancy, and the disproportionately large baby-boom generation born between 1946 and 1964 (Craig \& Paganelli, 2000), most countries in the Western world are currently experiencing a substantial demographic change of their populations, which is also mirrored in the increasing age diversity

We thank our Action Editor, Hui Liao, and two anonymous reviewers for their constructive and helpful comments in the review process of this article. We also acknowledge the feedback and support from Lisa Nishii and Sim Sitkin. The research described in this article was supported by grants received from the MyHandicap Foundation from Switzerland and the Hans-Boeckler-Foundation from Germany.

Correspondence and requests for reprints should be addressed to Stephan A. Boehm, Center for Disability and Integration, University of St. Gallen, Rosenbergstrasse 51, CH9000 St. Gallen, Switzerland; stephan.boehm@unisg.ch. 
of their workforces (Dychtwald, Erickson, \& Morison, 2004; Tempest, Barnatt, \& Coupland, 2002). From 2006 to 2016, the group of 55- to 64-year-old workers in the U.S. workforce is projected to increase by $37 \%$ (U.S. Bureau of Labor Statistics, 2008). Similar numbers apply to Germany. From 2020, older employees (50-65) will represent the German working population's largest subgroup $(40.2 \%$ of the total working population in Germany; Destatis, 2009). In many organizations, different individuals from three or even four generations will work together. As a consequence, ways to achieve the joint engagement of these diverse age groups will be a key factor in the future success of companies.

One important factor in reaching the high productivity of all age groups may be an organization-wide age-diversity climate, best described as employees' shared perceptions of an organization's diversity-related policies, practices, and procedures (Gelfand, Nishii, Raver, \& Schneider, 2005; Kossek \& Zonia, 1993; Pugh, Dietz, Brief, \& Wiley, 2008) in terms of age. Although research on general diversity climate is apparently emerging from its "embryonic stage" (Van Knippenberg \& Schippers, 2007, p. 532), more distinct forms of diversity-related climate perceptions have still not attracted the attention they deserve. In particular, the concept of age-diversity climate has_to our knowledge_-not yet been studied in any theoretical or empirical context. Given the practical importance of the demographic change and the rising age diversity in most developed countries, this is a serious shortcoming of the literature. As Schneider, Ehrhart, and Macey (2011) argue, scholars should strive for a best possible match between the climate they study and the antecedents and effects they predict in order to gain a high predictive validity of their model. In other words, if one is interested in the role of age in the workplace, it might be more revealing to develop and test a nomological net of age-diversity climate than of general diversity climate. Therefore, this study aims to establish such a new climate measure while equally investigating potential antecedents and consequences at the organizational level.

First, we draw from work on general diversity climate (e.g., Gonzalez \& DeNisi, 2009; Kossek \& Zonia, 1993; McKay, Avery, Liao, \& Morris, 2011; Mor Barak, Cherin, \& Berkman, 1998) as well as that on older employees (e.g., Armstrong-Stassen \& Lee, 2009; Kooij, Jansen, Dikkers, \& De Lange, 2010) to develop a sound definition and empirical validation of the age-diversity climate construct at the organizational level of analysis.

Second, we follow recent calls to "conduct studies to uncover the HR practices associated with pro-diversity climates" (Avery \& McKay, 2010, p. 242). More specifically, we will define and validate a measure of age-inclusive human resource practices as a potential antecedent of an 
organizational age-diversity climate. Building upon the work of Kopelman, Brief, and Guzzo (1990) and applying arguments from theories of signaling and collective sensemaking (Casper \& Harris, 2008; Den Hartog, Boselie, \& Paauwe, 2004; Ostroff \& Bowen, 2000), we assume that human resource (HR) practices, which are adjusted to an age-diverse workforce (e.g., Armstrong-Stassen \& Lee, 2009; Armstrong-Stassen \& Schlosser, 2011; Armstrong-Stassen \& Templer, 2006), are positively related to age-diversity climate.

Third, we strive to establish age-diversity climate as a performance antecedent on the organizational level of analysis. Although different types of climate have been reported to be relevant for individual-, group-, or unit-level outcomes (e.g., Gelade \& Ivery, 2003; Gonzalez \& DeNisi, 2009; McKay et al., 2011), no study to our knowledge has investigated the organizational-level consequences of diversity climate (McKay, Avery, \& Morris, 2009). Given the ongoing discussion on the "business case for diversity" (Robinson \& Dechant, 1997, p. 21), this seems to be one of the major gaps in diversity climate research, calling for a detailed empirical inspection of across-firm differences with regard to diversityrelated performance effects (Avery \& McKay, 2010). Thus, building upon Cox's (1994) interactional model of cultural diversity (IMCD), we will employ social exchange theory to argue for a positive relation of a pronounced age-diversity climate with firm-wide perceptions of social exchange, which in turn relate positively to the performance of an organization as well as negatively to employees' collective turnover intentions.

Finally, by establishing a model that assumes an indirect relationship of age-inclusive HR practices via age-diversity climate on company outcomes, we also strive to contribute to the HRM literature. In the past decade, HRM research has made significant progress in opening the "black box" between certain bundles of HR measures and firm performance (see Combs, Liu, Hall, \& Ketchen, 2006; Lepak, Liao, Chung, \& Harden, 2006 for theoretical and empirical reviews). More specifically, recent research has shed light on the role of climates as intermediating variables between HR practices and company outcomes (e.g., Chuang \& Liao, 2010; Collins \& Smith, 2006; Takeuchi, Lepak, Wang, \& Takeuchi, 2007). Our study builds upon this work and extends it by (a) introducing and validating age-inclusive HR practices as a novel HR system for achieving a distinct strategic goal (i.e., fostering a positive age-diversity climate) and (b) by exploring how age-diversity climate as a new mediator translates its potential effects on firm-level outcomes such as productivity or collective turnover intentions. By doing so, we also follow a recent call by Lepak et al. (2006) to investigate if HR systems for specific organizational objectives exist, such as fostering diversity perceptions within firms. 
In sum, our paper aims to further integrate research on both diversity climate and the HRM-performance link through testing two three-path mediation relationships in a sample of 93 companies with 14,260 employees. By doing so, we hope to contribute toward a better understanding of how inclusive HR practices-especially those targeted toward age diverse employees - may have an impact on firm performance and employee turnover through the creation of a positive age-diversity climate and collective perceptions of social exchange.

\section{Theory}

\section{The HRM-Organizational Climate-Firm Performance Link}

In the past decade, theoretical and empirical research has proposed and demonstrated a positive association between well-developed HR practices and organizational performance (Arthur, 1994; Becker \& Huselid, 1998; Huselid, 1995; Zacharatos, Barling, \& Iverson, 2005). Most scholars agree, however, that instead of affecting organizational performance directly, HR practices may rather lead to certain intermediate processes including desirable employee states and behaviors (e.g., Chuang \& Liao, 2010; Ferris et al., 1998; Gardner, Wright, \& Moynihan, 2011).

Kopelman et al. (1990) were among the first to focus on the mediating role of climate in the HRM-performance link. This line of thought was adopted by scholars such as Ostroff and Bowen (2000; Bowen \& Ostroff, 2004), who developed a theoretical model proposing a positive effect of HRM practices on firm performance via the creation of strong climates. They explain that in order to be effective, organizations should strive for a high alignment between the HR practices they design and the goals they want to achieve (such as fostering a distinct climate).

In the meantime, scholars started to empirically test and support such HRM-climate performance relationships (e.g., Chuang \& Liao, 2010; Collins \& Smith, 2006; Takeuchi et al., 2007). Our study builds upon this work and translates it to the particular context of age-diversity climate, which we propose as an important mediator in the age-inclusive HR practices-firm performance relationship.

\section{"Age-Diversity Climate" Defined}

Work on diversity climate can be traced back to the original definition of Reichers and Schneider (1990, p. 22), who defined "organizational climate" as "shared perceptions of the way things are around here." The authors describe organizational climate perceptions as evolving as part of 
a sensemaking process in which salient workplace stimuli (e.g., certain workplace conditions, organizational events, and management behavior) are retrieved and interpreted by the workforce. If shared among organizational members, joint perceptions of a distinct climate may evolve (Reichers \& Schneider, 1990; Schneider \& Reichers, 1983). Most scholars agree with Schneider and Reichers (1983) that climate is most meaningful if it is specified in terms of having a distinct referent, for example, a climate for safety (Zohar, 2000) or for cooperation (Collins \& Smith, 2006).

Most relevant for our study on age-diversity climate is the concept of general diversity climate, which was introduced by scholars such as Kossek and Zonia (1993) and Mor Barak et al. (1998). Gelfand et al. (2005, p. 104) defined it as 'employees' shared perceptions of the policies, practices, and procedures that implicitly and explicitly communicate the extent to which fostering and maintaining diversity and eliminating discrimination is a priority in the organization."

Based on this definition, we understand age-diversity climate as a specific form of a more general diversity climate and define it as organizational members' shared perceptions of the fair and nondiscriminatory treatment of employees of all age groups with regard to all relevant organizational practices, policies, procedures, and rewards. In practice, it covers members' joint impression that their organization favors an age-diverse workforce and takes active steps to recruit, promote, and retain employees of all age groups. Moreover, it reflects a shared conviction that age is no potential stumbling block in making progress within the organization. In our opinion, it is important to stress that such a pronounced age-diversity climate reflects an age-neutral organizational behavior toward all groups; that is, not only should older employees feel free from age-related discrimination but so should younger workers (e.g., perceiving no disadvantages from seniority rules).

\section{Age-Inclusive HR Practices}

In line with prior research, we argue that in order to achieve a distinct climate (e.g., a positive age-diversity climate), organizations must install suitable and focused HR practices (Bowen \& Ostroff, 2004). Therefore, we draw from work on HR practices for an aging workforce that have been discussed in both research and practice over the past two decades (e.g., Armstrong-Stassen \& Lee, 2009; Armstrong-Stassen \& Templer, 2006; Patrickson \& Hartmann, 1995; Saba, Guérin, \& Wils, 1998). Most scholars dealing with this topic have proposed to introduce no single, isolated practices but certain bundles of age-related HR practices that are interrelated, internally consistent and based on a certain organizational 
logic (Kooij et al., 2010; see also Lepak et al., 2006; MacDuffie, 1995). However, the majority of the existing studies on age related HR practices were rather practice oriented and did typically not include a scale validation. In addition, almost all existing studies focused on HR practices designed only for older workers such as "targeting older employees to update current job skills" (Armstrong-Stassen \& Templer, 2006, p. 251). As we are interested in HR practices that might nurture a positive agediversity climate (and not a positive climate only for older employees), we felt the need to develop and validate a new scale that reflects this claim of age inclusion. In order to do so, we still drew from existing work on HR practices for older employees and adapted it to the needs of fostering an age diverse workforce.

Second, we drew from Avery and McKay's (2010) listing of practices likely to be associated with pro-diversity work climates ("valid selection systems, extensive trainings programs, employee participation, cooperation, formal performance appraisal systems, and merit-based promotions," p. 242) as a further basis for our item development.

Third, we combined these lines of research with the literature on strategic human resource systems (see e.g., Lepak et al., 2006) that typically argues that HR systems may impact organizational outcomes directly and indirectly by influencing (a) employees' skills and knowledge bases, (b) employees' motivation and effort, as well as (c) employees' opportunities to contribute to organizational goals (Batt, 2002; Delery \& Shaw, 2001; Lepak et al., 2006; MacDuffie, 1995).

Based on this conceptualization, we propose that in order to have a maximum effect, bundles of age-inclusive HR practices should relate to all three HR policy domains. Consequently, they should equally foster (a) all employees' (irrespective of their age) knowledge, skills, and abilities; (b) motivation and effort; and (c) opportunities to contribute (Lepak et al., 2006). With regard to HR policy domain 1 (knowledge, skills, and abilities), age-inclusive HR practices might include age-neutral recruiting activities as well as equal access to training and further education for all age groups. In this way, organizations can make sure that all age groups have the necessary knowledge and skills to perform their jobs successfully and ultimately contribute to firm performance.

With regard to HR policy domain 2 (motivation and effort), ageinclusive HR practices might include equal opportunities to be promoted, transferred, and to make further career steps irrespective of one's age. In addition, training and educating managers on how to deal with an agediverse workforce and how to respond to the needs of different age groups might also be an important lever of employee motivation. By engaging in such practices, firms can ensure that all age groups do not only have the skills but also the necessary motivation to contribute to joint goals. 
Finally, with regard to HR policy domain 3 (opportunities to contribute), age-inclusive HR practices might include the promotion of an age-friendly organizational culture that promotes and values the contribution of all age groups. Such an age-inclusive culture should help to provide all employees with the courage to speak up, to bring in their own ideas, and to help improve organizational creativity and effectiveness. In sum, organizations interested in effectively managing an age-diverse workforce should make sure that their age-inclusive HR practices ideally cover all three HR policy domains and take into account the needs of both younger and older employees, and not exclusively those of certain age groups.

\section{Relationship of Age-Inclusive HR Practices With Age-Diversity Climate}

Building upon theories of signaling and collective sensemaking (Casper \& Harris, 2008; Ostroff \& Bowen, 2000), we hypothesize that organizational members perceive such age-inclusive HR measures that are targeted toward the development of an age-diverse and age-embracing workforce. Den Hartog et al. (2004) explain how HR policies can function as a signal of the organization's intention toward its workers. Similarly, Bowen and Ostroff (2004) describe how HRM systems may explicate to employees what is collectively desired and expected from them. If employees experience that newly hired colleagues in their department are coming from all age groups and that employees have equal opportunities to be promoted and to get training, then they may perceive these as clear signals that the organization is interested in attracting and retaining an age-diverse workforce. In addition, HR practices that educate executives about the need for an inclusive leadership behavior as well as an appreciation of the particular contribution of all age groups' may be interpreted as clear signals of an age-friendly climate.

Organizational members are believed to interpret these signals and to collectively make sense (Schneider, 1990, 2000) of such age-inclusive behavioral guidelines. As the management (e.g., HR) is taking a credible interest in the proactive engagement of employees of all age groups, it can be expected that the organizational members themselves understand that the fostering of age diversity as well as the prevention of any age-related discrimination are major corporate goals. This should have a positive impact on both their own behavior toward members of different age groups and on the shared age-diversity climate within the organization. On the basis of these arguments, we suggest the following:

Hypothesis 1: Age-inclusive HR practices will be positively related to respondents' perceptions of age-diversity climate. 
Relationship of Age-Diversity Climate With Company Performance and Collective Turnover Intentions via Collective Perceptions of Social Exchange

In order to argue for a potentially positive effect of age-diversity climate on company performance and collective turnover intentions, we generally draw from Kopelman et al.'s (1990) climate model of firm productivity. This model proposes that climate impacts firm performance through its positive effects on desirable cognitive and affective states (e.g., work motivation) as well as relevant organizational behaviors (e.g., commitment or citizenship). Similarly, Cox's (1994) IMCD argues that a positive diversity climate should first affect individual affective and performance outcomes (such as job satisfaction or job performance ratings), which in turn should have a positive impact on first-level (e.g., turnover) and second-level organizational outcomes (e.g., profitability). In the meantime, there is also considerable empirical support for such positive relationships of diversity climate with collective performance (McKay et al., 2009) or customer satisfaction (McKay et al., 2011) as well as for a negative relationship with turnover intentions (McKay et al., 2007). In our study, we build upon this line of research and further specify it by introducing social exchange relationships of the employees with their companies as an often assumed, however seldom tested, mediator of the diversity climate-firm outcomes link.

Relationship of age-diversity climate with collective perceptions of social exchange. If a pronounced age-diversity climate exists within a firm, employees are more likely to perceive a fair treatment by their organization. They will experience that no preferential treatment is given to any employee based on his or her age and that all age groups receive equal levels of support by the organization, expressed in equal access to training, comparable development and promotion opportunities, and so on. This sense of being taken care of regardless of their age should foster all employees' (a) feelings of justice, (b) trust in their employer, (c) belief that the organization significantly invests in them, (d) long-term orientation toward their employment relationship, and (e) conviction that they receive socioemotional support and not only a financial compensation. All these potential implications of a distinct age-diversity climate in the workplace are important antecedents or even characteristics of social exchange relationships (Blau, 1964; Shore, Tetrick, Lynch, \& Barksdale, 2006).

As described by Blau (1964), social exchanges involve mutual obligations such that, when one party is doing a favor to another, there is an expectancy of some future return. As the exact form and point in time of the future return are often diffuse, trust and a long-term orientation are key to social exchange relationships (Konovsky \& Pugh, 1994; 
Shore et al., 2006). Perceived justice also has been found to be an important predictor of high-quality social exchange relationships (Masterson, Lewis, Goldman, \& Taylor, 2000; Moorman, Blakely, \& Niehoff, 1998; Wayne, Shore, Bommer, \& Tetrick, 2002), which involve mutual investments between both partners as well as a concern for the interest of the other party in the respective relationship (Blau, 1964; Shore et al., 2011).

In sum, organizations characterized by a pronounced age-diversity climate are more likely to be perceived as just, trustworthy, investing in its employees, and long-term orientated, which should foster employees' collective perception of a strong social exchange relationship between themselves and their employer. This assumption is in line with theoretical work of Shore et al. (2011), who proposed that inclusive climates should trigger perceptions of fairness and trust, which are important for developing social exchange relationships. Moreover, from an empirical point of view, Shore et al. (2011) showed that employees who perceive their organization to be committed toward them (i.e., perceiving high organizational support) reported higher levels of social exchange with their firm. Takeuchi et al. (2007) found evidence for such a relationship also on the collective level of analysis, indicating that employees can develop shared social exchange perceptions within their establishments or organizations.

Based on these arguments, we hypothesize:

Hypothesis 2: Age-diversity climate will be positively related to collective perceptions of social exchange.

Relationship of collective perceptions of social exchange with company performance and collective turnover intentions. Taking this process one step further, employees should not stop by just perceiving a heightened level of social exchange in the workplace.

Compared to more short-term and impersonal economic exchanges, social exchanges are based on a norm of reciprocity (Gouldner, 1960), which implies that "(1) people should help those who have helped them, and (2) people should not injure those who have helped them" (p. 171). Transferred to an organizational context, employees perceiving high social exchange should reciprocate their organizations' efforts through own intensified work-related endeavors with positive effects for their work performance, their organizational commitment, and their attachment (Aryee, Budhwar, \& Chen, 2002; Cropanzano \& Mitchell, 2005; Eisenberger, Huntington, Hutchison, \& Sowa, 1986; Shore \& Wayne, 1993). Supporting this assumption, Tsui, Pearce, Porter, and Tripoli (1997) showed that employees who perceive their relationship with their organization as characterized by mutual investments performed better on core tasks, 
exhibited more pronounced organizational citizenship behaviors and reported a higher intent to stay.

In addition, positive perceptions of high social exchange should not only increase employees' willingness to contribute to organizational goals but should also positively affect their willingness to support colleagues. Takeuchi et al. (2007, p. 1071) explain how high degrees of social exchange should spur social support among coworkers, leading to "positive synergies" between group members and ultimately to increased organizational performance (see also Podsakoff, Ahearne, \& MacKenzie, 1997). In sum, a balanced, fair, and reciprocal relationship between employees and the organization (expressed through high levels of collective perceptions of social exchange) seems likely to trigger behaviors above and beyond the call of duty, with positive effects for coworkers, customers, and other relevant organizational stakeholders that ultimately impact firm performance and collective turnover intentions.

There is also empirical work that has shown that social exchange perceptions and performance/reduced turnover are related on both the individual (Tsui et al., 1997) and collective level of analysis (Takeuchi et al., 2007). As a most important finding for our study, Takeuchi et al. (2007) demonstrated a positive relation between the degree of social exchange collectively perceived in an establishment and establishment performance. Based on the theoretical and empirical arguments presented above, we propose the following:

Hypothesis 3: Collective perceptions of social exchange will be positively related to company performance.

Hypothesis 4: Collective perceptions of social exchange will be negatively related to collective turnover intentions.

\section{Mediation Hypotheses}

Hypothesis 1 predicts a positive influence of age-inclusive HR practices on age-diversity climate. Hypothesis 2 predicts a positive relationship between age-diversity climate and collective perceptions of social exchange. Hypotheses 3 and 4 predict a positive relationship between collective perceptions of social exchange and company performance, and a negative one with collective turnover intentions, respectively. Together, these hypotheses specify a model in which age-inclusive HR measures indirectly influence company performance and collective turnover intentions by contributing to organizational members' joint perception of a pronounced age-diversity climate and social exchange level. This view is consistent with recent HRM research that has consistently made use 
of climates as mediators between bundles of HR practices and firm performance (e.g., Chuang \& Liao, 2010; Collins \& Smith, 2006; Lepak et al., 2006; Ostroff \& Bowen, 2000; Takeuchi et al., 2007). By introducing age-diversity climate and collective perceptions of social exchange as potential mediators, we build upon this work and hope to shed more light on the relationship between age-inclusive HR practices and organizational outcomes, which has received an insufficient amount of attention to date. Consequently, we propose the following three-path mediation hypotheses:

Hypothesis 5: The relationship between age-inclusive HR practices and company performance is mediated through a firm's agediversity climate and collective perceptions of social exchange.

Hypothesis 6: The relationship between age-inclusive HR practices and collective turnover intentions is mediated through a firm's age-diversity climate and collective perceptions of social exchange.

\section{Method}

Sample

Data for this study were collected as part of a larger benchmarking study for German small and medium-sized companies. The data collection was conducted by an agency specialized in benchmarking reports for small and medium-sized companies. To be eligible for the study, companies had to be located in Germany and employ less than 5,000 employees. Of the 110 primarily contacted companies, 17 refused to participate at all or did not provide any information on the age-inclusive HR practices, resulting in an organizational level response rate of $85 \%(n=93) .{ }^{1}$ Participating

\footnotetext{
${ }^{1}$ In order to increase the power for our model testing and to achieve a sufficient sample size for the SEM testing, we tried to limit the drop outs in our sample by applying pairwise instead of listwise data deletion techniques if one of the mediators, dependent variables, or control variables had missing values. Applying listwise deletion techniques would imply to lose the whole case, if for example information about one control variable would be missing. Consequently, we applied the recommendation from Enders and Bandalos (2001), who argued - after running simulation studies - that both pairwise deletion and full information maximum likelihood (FIML) are more reliable in estimating model fit and parameter estimates, especially in smaller samples. Thus we calculated our SEM models using a covariance matrix based on pairwise deletion. In addition, we checked the robustness of our results by using FIML imputation techniques based on raw data, which did not change the overall pattern of our results. Results of this robustness check are available upon request from the first author.
} 
companies ranged in number of employees from 12 to 3,265 (mean $=292)$ and came from a variety of industries, including service $(61 \%)$, production (19\%), trade (10\%), and finance and insurance (5\%).

To ensure equivalence of data collection, similar methods were applied across all companies in three steps. Study variables were collected from six different data sources (one HR director survey, one top management team [TMT] survey, and four employee surveys) in order to rule out concerns about same source bias (Podsakoff, MacKenzie, \& Podsakoff, 2012).

First, the organizations' HR executives completed a survey asking for general information about the company (e.g., industry affiliation, company size as controls) and specific HR procedures, including the age-inclusive HR practices relevant for this study as well as the firm's innovation capacities (as a control variable).

Second, employees were asked to obtain information on the perceived age-diversity climate, collective perceptions of social exchange, collective turnover intentions, and the positive affective climate (as a control variable). For that purpose, participating organizations sent a standardized email invitation through their HR department, if available, or a top management team member's account. This mail explained the study's purpose and provided a weblink to the survey hosted by an independent third company. A paper version of the questionnaire was provided for employees with no Internet access. Overall, 14,260 employees returned the questionnaire, which indicates a within-organization response rate of $71 \%$. As the participants had to answer a larger number of questions for the benchmarking report, and to avoid concerns about common method bias (Podsakoff et al., 2012), a study design was applied that limited the amount of questions for each employee and consequently prevented a high incidence of nonresponse. For that reason, participants were randomly assigned to four different versions of the survey, based on an algorithm on the website: For our study, Version 1 of this survey assessed only demographic variables of the respondents, with age and tenure being relevant as control variables for our study; Version 2 captured the items for positive affective climate (as a control variable) in addition to demographic variables; Version 3 captured the items for the age-diversity climate and collective perceptions of social exchange in addition to demographic variables; and Version 4 assessed employees' collective turnover intentions and demographic characteristics. Respondents were equally represented as to gender. The average age was $38(S D=4)$, and respondents had worked on average 7 years for their companies $(S D=3.8)$.

As our third main data source, members of the companies' executive boards were surveyed with an additional questionnaire mainly addressing company performance issues. This proceeding was chosen based on the assumption that executive board members should be the best source 
regarding company performance information. In all companies, between one and nine executive board members participated. The top management team members were mostly male ( $85 \%)$, worked on average 12 years for their company $(S D=8.2)$, and were on average 45 years old.

\section{Measures}

The exact wording of the study's focal measures is provided in the Appendix.

Age-inclusive HR practices. Following Avery and McKay's (2010, p. 245) advice to "choose valid, reliable informants as sources of HR practices data (e.g., HR directors or line managers)," the data on age-inclusive HR practices were obtained from the organizations' top HR representatives. As explained in our theory section, we had to design new items because no validated scale for age-inclusive HR practices existed in the literature, to our knowledge. Based on existing conceptual and descriptive studies on managing older employees (e.g., Armstrong-Stassen \& Templer, 2006), Avery and McKay's (2010) listing of practices likely to be associated with pro-diversity work climates, as well as findings from the strategic HR literature on the three major HR policy domains (e.g., Lepak et al., 2006), we created five items with a five-point Likert scale $(1=$ very low intensity; $5=$ very high intensity) to gauge a variety of organizational HR practices related to developing an age-inclusive workforce. These items included (a) age-neutral recruiting activities; (b) equal access to training and further education for all age groups; (c) equal opportunities to be promoted, transferred, and to make further career steps irrespective of one's age; (d) training and education for managers on how to deal with an age-diverse workforce and how to respond to the needs of different age groups; as well as (e) the promotion of an age-friendly organizational culture (sample item: With how much intensity does your company offer equal opportunities to be promoted, transferred, and to make further career steps irrespective of one's age?).

As this was a newly developed measure, we used a second independent dataset to establish the unidimensional structure. This dataset consisted of 108 German small and medium-sized firms (average company size $=$ 401 employees) and was collected with the same procedures but in a different year than the main dataset for the study. For our purpose, we only used the information provided by the 108 top HR representatives, who filled in the information about the age-inclusive HR practices. First we performed an exploratory factor analysis (EFA), which indicated a clear one-factor solution with an eigenvalue of 2.28 and no eigenvalue of another factor above 1.0. In a varimax rotation solution the five items 
showed an average loading of .67 on this one factor with no factor loading below .50. In a second step, we performed a confirmatory factor analysis (CFA) with the additional dataset. To assess the model fit we followed the recommendation by $\mathrm{Hu}$ and Bentler (1999) for small samples (e.g., below 250) such as ours to use the standardized root mean square residual (SRMR) index in combination with two incremental fit indices, such as the comparative fit index (CFI) and the incremental fit index (IFI). The results indicated sufficient model fit properties $\left(\chi^{2}=15, d f=5\right.$; CFI $=$ $.90, \mathrm{IFI}=.90, \mathrm{SRMR}=.07)$. Although values for the IFI and CFI should at least be above .90 for a reasonable model fit, the SRMR should be below .08 for a reasonable fitting model (Cheung \& Rensvold, 2002; Hu $\&$ Bentler, 1999). In a third step to further establish the new measure, we again performed a separate CFA in the study's main dataset. The results of this CFA were satisfactory $\left(\chi^{2}=9, d f=6\right.$; CFI $=.97$, IFI $=.97$, SRMR $=.06$ ). Finally, the internal consistency was $\alpha=.66$.

Age-diversity climate. Age-diversity climate was measured with a seven-point Likert scale in employee Version 3, applying four items that were closely related to the general diversity measure developed by Pugh et al. (2008). The four items were rephrased to address only specific age-diversity issues instead of general diversity as in the original scale (sample item: Managers in our company demonstrate through their actions that they want to hire and retain an age-diverse workforce).

As this measure was also newly developed for this study, we also undertook additional validation efforts. First, we used information from 11 companies who were dropped from the analysis because they did not return the HR-representative questionnaire but in which 292 employees (mean age $=38$ years; mean tenure $=7$ years; $56 \%$ male) overall provided information about the age-diversity climate. With this additional data, we first performed an EFA, which proposed a one-factor solution with an eigenvalue of 2.38 and no eigenvalue for a further factor being above the threshold of 1.0. In a varimax rotation solution, the four items showed an average loading of .825 on this one factor, with no item showing a loading below .50. Second, we also conducted a CFA with the additional dataset. This analysis showed a sufficient fit of the new measure to the data $\left(\chi^{2}=\right.$ $.65, d f=2 ; \mathrm{CFI}=1.0, \mathrm{IFI}=1.0, \mathrm{SRMR}=.00)$. Third, we also ran a CFA in our main dataset to inspect the fit of the proposed single-factor structure to the data. Results indicate a sufficient fit of the model to our data $\left(\chi^{2}=1, d f=2 ; \mathrm{CFI}=1.0, \mathrm{IFI}=1.0, \mathrm{SRMR}=.01\right)$. Fourth, we also tested if the new age-diversity climate measure was distinct to existing general diversity climate measures. For this purpose we used information from 20 companies that were present in this study and from which we also collected data on a general diversity climate measure (McKay, Avery, \& Morris, 2008) and company performance in another data collection 
2 years later. For these 20 companies we first calculated a measurement model with the four age-diversity climate items and the five general diversity climate items loading on separate constructs, which showed good overall fit properties $\left(\chi^{2}=27, d f=26\right.$; CFI $=1.00$, IFI $=1.00$, $\mathrm{SRMR}=.04)$. An alternative model with all nine diversity climate items loading on a joint measure had a significantly worse fit $\left(\Delta \chi^{2}=50, \Delta d f=\right.$ 1 ), indicating a good discriminatory validity of the measures. In addition, we inspected the predictive validity of the two diversity measures by relating them to an overall company performance measure collected at the second time point from the top managers of each company (wording of the item: How would you evaluate the overall performance of your company compared to your direct competitors?). The structural relationships with the general company performance were significant for both age-diversity climate $(\beta=.63, t=3.54, p<.001)$ and the general diversity climate measure $(\beta=.55, t=3.08, p<.01)$, showing that age-diversity climate explains $15 \%$ of variance in company performance beyond the effect of the general diversity climate. In sum, we assume to have established sufficient discriminatory and predictive validity for our new age-diversity climate construct. Internal consistency estimates were $\alpha=.91$.

To empirically justify the aggregation of the individual answers to the organizational level, we calculated intraclass correlation coefficients $\left(\mathrm{ICC}_{1}\right.$ and $\left.\mathrm{ICC}_{2}\right)$ following the recommendations made by Bliese (2000) and the average deviation index as an interrater agreement ratio $\left(\mathrm{AD}_{\mathrm{M}(\mathrm{J})}\right.$; Burke, Finkelstein, \& Dusig, 1999). The $\mathrm{ICC}_{1}$ indicates the existence of a group effect on the variable of interest, whereas the $\mathrm{ICC}_{2}$ estimates the reliability of the group means (Bliese, 2000). For the $\mathrm{ICC}_{1}$, values that are based on a significant one-way analysis of variance are generally acceptable. For the $\mathrm{ICC}_{2}$, values of more than .60 are usually considered sufficient (e.g., Chen, Mathieu, \& Bliese, 2004). The $\mathrm{AD}_{\mathrm{M}(\mathrm{J})}$ has several advantages over the more frequently used $r_{w g}$ Index. First, the index does not require modeling a random or null response distribution. Second, it provides estimates in the metric of the original scale; and third, an upper-level cutoff criteria of $\mathrm{c} / 6$ (where $c$ equals the number of response categories of the response scale) was provided and statistically justified by Burke and Dunlap (2002). In our case, all three statistics showed sufficient results $\left(\mathrm{ICC}_{1}=.13, p<0.001 ; \mathrm{ICC}_{2}=.84\right.$; mean $\left.\mathrm{AD}_{\mathrm{M}(\mathrm{J})}=.82\right)$, suggesting that aggregation to the company level was a reasonable procedure.

Collective perceptions of social exchange. We measured collective perceptions of social exchange in the employee survey version 3 by applying four items from the five-item scale of Takeuchi et al. (2007). A sample item was: "Employees in our company don't mind working hard todaythey know they will eventually be rewarded by our company" ( $1=$ totally disagree; $5=$ totally agree). A separate CFA of the shortened measure 
showed good fit properties $\left(\chi^{2}=15, d f=2 ; \mathrm{CFI}=97, \mathrm{IFI}=.97, \mathrm{SRMR}=\right.$ $.03)$. Aggregation statistics also provided support for an aggregation to the organizational level of analysis $\left(\mathrm{ICC}_{1}=.19, p<0.001 ; \mathrm{ICC}_{2}=.90\right.$; mean $\left.\mathrm{AD}_{\mathrm{M}(\mathrm{J})}=.60\right)$. Internal consistency estimates were $\alpha=.96$.

Company performance. To capture organizational performance, we followed Combs, Crook, and Shook's (2005) suggestion to differentiate between operational and organizational performance. As recently applied by Kunze and colleagues (Delaney \& Huselid, 1996; Kunze, Boehm, \& Bruch, 2011, 2013), we asked the company board members to assess three items on organizational performance (i.e., company growth, financial performance, return on assets) and two on operational performance (i.e., employee productivity, efficiency of business procedures). In line with prior studies (Rogers \& Wright, 1998), the perceptual measures were benchmarked in the sense that we asked key informants to assess firm performance relative to the performance of their industry rivals on a seven-point scale $(1=$ far below average $7=$ far above average $)$. We are, however, aware that forward-looking stock measures would be the most desirable source to evaluate organizational performance; however, for our specific sample, it was almost impossible to collect such data because most of the companies are privately owned and thus do not provide public data, which are the most common source for market measures. In addition, empirical research has shown the validity of subjective measures and thus provides support for their application to the measurement of organizational and operational performance (Kunze et al., 2011, 2013; Rowe \& Morrow, 1999; Wall et al., 2004).

As in previous research (Dickson, Resick, \& Hanges, 2006; Sine, Mitsuhashi, \& Kirsch, 2006), we constructed a latent measure for company performance with organizational and operational performance as two sub-dimensions. We also checked the aggregation statistics for the companies in which more than one board member answered $(n=53)$, which overall supported an aggregation to the company level $\left(\mathrm{ICC}_{1}=.35 ; p<\right.$ $0.001 ; \mathrm{ICC}_{2}=.65 ;$ mean $\left.\mathrm{AD}_{\mathrm{M}(\mathrm{J})}=.50\right)$. The internal consistency estimate was $\alpha=.93$.

Employees' collective turnover intentions. Employees' collective turnover intentions were assessed in the employee survey version 4. As in prior studies (e.g., Côté \& Morgan, 2002; Harris, Kacmar, \& Witt, 2005), we captured employees' individual turnover intention with a one-item measure designed by Spector, Dwyer, and Jex (1988). We asked employees on a five-point scale $(1=$ never; $5=$ extremely often/always $)$ how often they have seriously considered quitting their job in the last 6 months. The answers were aggregated on the organizational level following the argumentation for collective turnover intentions by Felps et al. (2009). The ICC values $\left(\mathrm{ICC}_{1}=.07 ; p<0.001 ; \mathrm{ICC}_{2}=.73\right.$; mean $\left.\mathrm{AD}_{\mathrm{M}(\mathrm{J})}=.81\right)$ 
indicated that an aggregation to the company level was a reasonable strategy.

Controls. We also included several control variables in our analysis. First, we controlled for mean age and age diversity (measured through the standard deviation) of the company, as previous research has shown that the age structure of the company is related to age discrimination in companies (Kunze et al., 2011, 2013). Second, as age is often highly interrelated with organizational tenure, we also controlled for mean tenure and tenure diversity (measured through the standard deviation) of the employees. Third, following prior studies that found that the diversity structure of the area, where a company is located, might affect perceptions of diversity climate (e.g., Pugh et al., 2008; Ragins, Gonzalez, Ehrhardt, \& Singh, 2012), we controlled for the mean age and the age diversity of the counties where the companies are located in. The German Federal Statistical Office provided us with the mean age of each county and the age structure in 5-year categories for each county, out of which we calculated a Blau index for age-diversity (Blau, 1977). ${ }^{2}$ Fourth, following prior organizational-level research (e.g., Delaney \& Huselid, 1996), we took two single items from the HR-key informant survey (a) to account for the percentage of employees who are members of a labor union and (b) to assess the participating organizations' market competition ("How strong is the competitive pressure your company experiences?"; 1 = extremely low, $7=$ extremely high ) because both may impact the company's performance (Huselid, 1995). Fifth, because organization size has been shown to be associated with various employee behaviors and outcomes (Ragins, Cotton, \& Miller, 2000), we included it as a control factor. As the measure was skewed, we log transformed it. Sixth, to increase the predictive validity of the new age-diversity climate measure, we controlled for two potentially related constructs (positive-affective climate and innovation capacities) that might also affect collective perceptions of social exchange within companies. Positive affective climate was measured with five items from the Job-Related Affective Well-Being Scale (JAWS; Van Katwyk, Fox, Spector, \& Kelloway, 2000). A sample item was: "Employees in this company feel excited at the workplace" $(1=$ totally disagree; $5=$ totally agree). Aggregation statistics $\left(\mathrm{ICC}_{1}=.07 ; p<0.001 ; \mathrm{ICC}_{2}=.73\right.$; mean $\left.\mathrm{AD}_{\mathrm{M}(\mathrm{J})}=.81\right)$ and the internal consistency estimates $(\alpha=.90)$ for this measure were sufficient. To optimize the degrees of freedom for the analyses we averaged the five items to form one manifest construct in the following SEM analysis. Innovation capacities were measured with two items

\footnotetext{
${ }^{2}$ The formula of the Blau index is $1-\Sigma p_{i}^{2}$, with $p$ as the age proportion of county members and $i$ as the number of different age categories represented within the county. The index can vary from 0 , signaling total absence of diversity, to a theoretical maximum of 1 .
} 
answered by the top HR-representative, which asked about (a) the general innovation capacities and (b) the capacities to implement innovation within the company compared to the direct competitors in the same industry $(1=$ far below average $; 7=$ far above average $)$. Both items were averaged to form one manifest construct for the analyses. Internal consistency values were sufficient with $\alpha=.86$. Seventh, following other research that proposes that older organizations are more productive on average (Choi \& Shepherd, 2005), we controlled for the companies' age by asking for the company's founding year. Finally, we classified the companies in four industries by coding dummy variables (Pierce \& Gardner, 2004).

\section{Analytical Procedures}

To test our study's hypotheses, we applied structural equation modeling methods with the statistical package Amos 18.0. In line with the classical approach by Anderson and Gerbing (1988), we carried out our data analysis in two separate steps. The reason for this is so as not to confound the meaning of the study results by a simultaneous estimation of the measurement and structural model. In the first analysis, we did a simultaneous confirmatory factor analysis for all study constructs to create a measurement model. In a second step, we analyzed a structural model that included the relationships stated in Hypotheses 1-6. To check for the proposed three-path mediation effects, we followed the proceeding described by Taylor, MacKinnon, and Tein (2008) and applied bootstrapping procedures to check for the significance of the indirect relationships (Cheung \& Lau, 2008).

\section{Results}

\section{Descriptive Statistics}

Table 1 presents means, standard deviations, and bivariate correlations for all study variables. The results show that, as hypothesized, (a) the age-inclusive HR practices are positively related to age-diversity climate $(r=.21, p<.05)$, (b) age-diversity climate is positively related to collective perceptions of social exchange $(r=.76, p<.001)$, (c) collective perceptions of social exchange are positively related to organizational performance $(r=.40, p<.001)$, and (d) collective perceptions of social exchange are negatively related to collective turnover intentions ( $r=$ $-.62, p<.001)$. The age-inclusive HR practices seem to be unrelated to organizational performance $(r=.20, n s)$ and collective turnover intentions $(r=-.11, n s)$. 


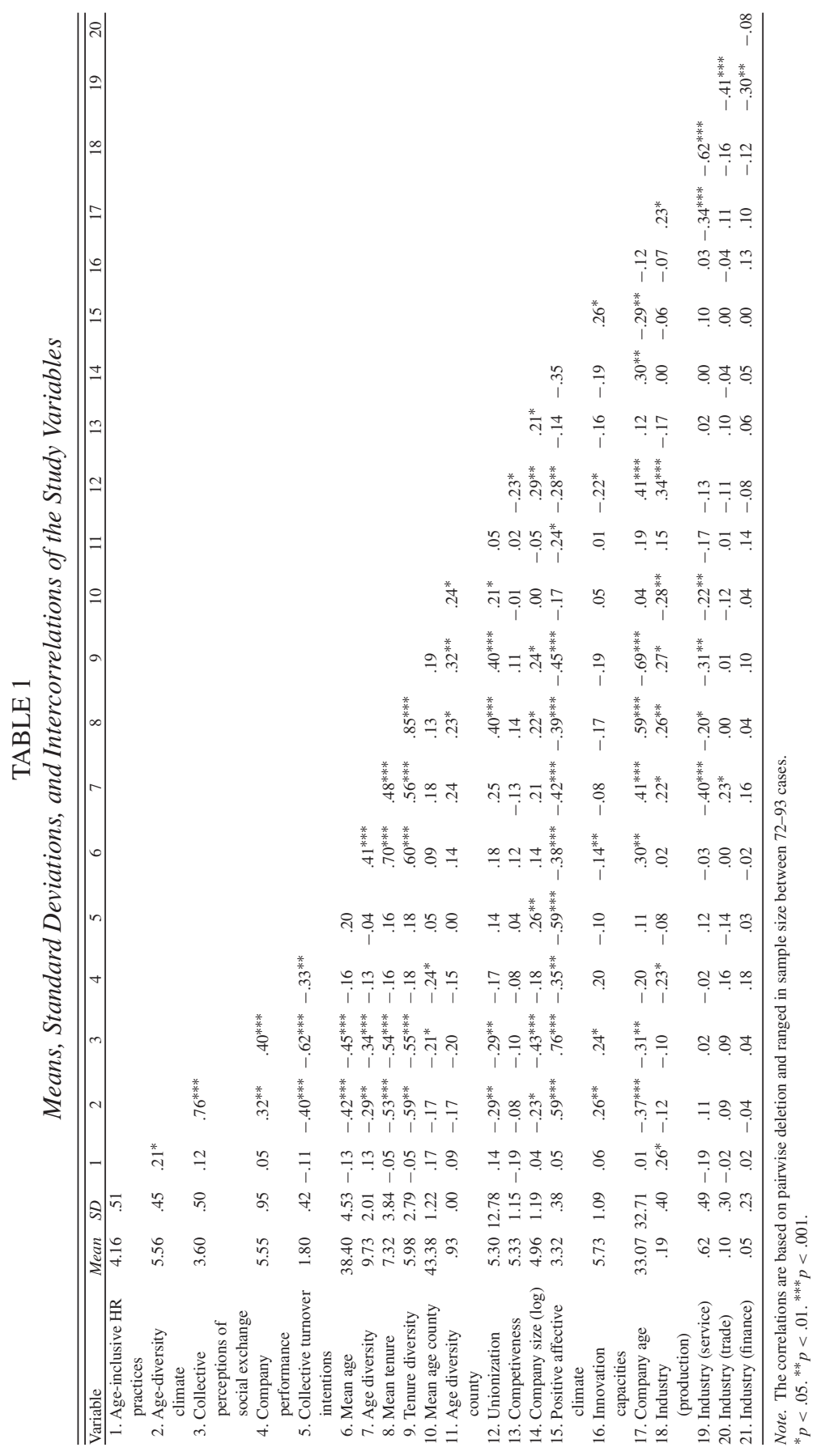


Regarding the control variables, mean age, age diversity, mean tenure, tenure diversity, mean age of the county, level of unionization, company size, positive affective climate, innovation capacities, company age, and industry production seem to be significantly related to our central study variables, but neither the age diversity of the county nor any of the other industry proxies are significantly correlated with one of the four outcome variables. Consequently, we decided to retain only those 11 significant variables in further analyses in order to reduce the number of parameters to be estimated and, thus, to achieve the maximum power for the following tests (Bedeian, 2007). Furthermore, unnecessary control variables are likely to cause biased parameter estimates (Becker, 2005). ${ }^{3}$

\section{Measurement Model}

The measurement model contained four latent constructs-ageinclusive HR practices, age-diversity climate, collective perceptions of social exchange, and company performance-with 19 items overall, as well as collective turnover intentions as a single-item construct. The indices of the overall model fit indicated a sufficient fit of our assumed structure to the data $\left(\chi^{2}=155, d f=98 ; \mathrm{CFI}=.96, \mathrm{IFI}=.96, \mathrm{SRMR}=\right.$ $.07, \mathrm{AIC}=259)$. To test for the discriminatory validity of our measures we specified four alternative models and compared them to our baseline model (see Table 2). First, to inspect the distinctiveness of the HR practices and age-diversity climate measures we specified an alternative model in which all respective items of these constructs loaded on one joint factor (alternative model 1) and that had a significantly worse fit, indicating a reasonable discrimination between these constructs. Second, we specified another alternative model in which the age-diversity climate and collective perceptions of social exchange items loaded on one common factor (alternative model 2). This alternative model also had a significantly worse fit compared to the assumed measurement model. As a third alternative model, we tested a model with the items of the independent variable (ageinclusive HR practices) and the mediators loading on one common factor (alternative model 3), which also showed significantly worse fit properties. Finally, we inspected a model (alternative model 4) with items from all constructs loading on one common factor that was also worse fitting compared to the assumed measurement model.

\footnotetext{
${ }^{3}$ To check the robustness of our results we also estimated an alternative model including all control variables (see alternative model 7 in Table 2), in which all our proposed relationships remained significant on a 5\% level.
} 
TABLE 2

Model Comparison

\begin{tabular}{|c|c|c|c|c|c|c|}
\hline Model & $\chi^{2}$ & $d f$ & $\chi^{2} / d f$ & $\Delta \chi^{2}$ & $\Delta d f$ & AIC \\
\hline \multicolumn{7}{|l|}{ Measurement models } \\
\hline Hypothesized measurement model & 155 & 98 & 1.58 & & & 259 \\
\hline $\begin{array}{l}\text { Alternative model 1: Age-inclusive HR } \\
\text { practices and age-diversity } \\
\text { climate one factor }\end{array}$ & 267 & 100 & 2.67 & $112^{*}$ & 2 & 371 \\
\hline $\begin{array}{l}\text { Alternative model 2: Age-diversity } \\
\text { climate and collective perceptions of } \\
\text { social exchange one factor }\end{array}$ & 260 & 101 & 2.57 & $105^{*}$ & 3 & 363 \\
\hline $\begin{array}{l}\text { Alternative model 3: Independent } \\
\text { variables and mediators one factor }\end{array}$ & 382 & 103 & 3.71 & $115^{*}$ & 5 & 480 \\
\hline Alternative model 4: All items one factor & 508 & 104 & 4.88 & $248^{*}$ & 6 & 604 \\
\hline \multicolumn{7}{|l|}{ Structural models } \\
\hline $\begin{array}{l}\text { Hypothesized model: Three-path } \\
\text { mediation model }\end{array}$ & 370 & 220 & 1.68 & & & 740 \\
\hline $\begin{array}{l}\text { Alternative model 1: Indirect-effects } \\
\text { only model }\end{array}$ & 373 & 224 & 1.67 & 3 & 4 & 735 \\
\hline $\begin{array}{l}\text { Alternative model 2: Only-direct effects } \\
\text { model }\end{array}$ & 431 & 227 & 1.90 & $61^{*}$ & 7 & 787 \\
\hline Alternative model 3: No-controls model & 480 & 252 & 1.90 & $110^{*}$ & 32 & 786 \\
\hline $\begin{array}{l}\text { Alternative model 4: Reversed-mediator } \\
\text { model }\end{array}$ & 423 & 225 & 1.88 & $53^{*}$ & 5 & 782 \\
\hline $\begin{array}{l}\text { Alternative model 5: Reversed-effect } \\
\text { model }\end{array}$ & 376 & 220 & 1.71 & $6^{*}$ & 0 & 746 \\
\hline $\begin{array}{l}\text { Alternative model 6: Age mean and age } \\
\text { diversity moderation }\end{array}$ & 490 & 273 & 1.79 & $120^{*}$ & 53 & 998 \\
\hline Alternative model 7: All-controls model & 450 & 275 & 1.64 & $80^{*}$ & 55 & 1018 \\
\hline
\end{tabular}

Note. $n=93$. The alternative measurement models compared to the measurement model, the seven structural models are compared to the mediation model.

${ }^{*}$ Chi-difference statistic $p<.05$ compared to the mediation model. The lowest value of the Akaike Information Criterion (AIC) indicates the best-fitting model.

\section{Structural Model}

In the second part of our analysis, we investigated the structural proportion of our assumed model. The main results are illustrated in Figure 1. As shown in Table 2, the overall results of the three-path mediation model suggested a good fit of the model to the data $\left(\chi^{2}=370, d f=220\right.$; $\mathrm{CFI}=$ $.92, \mathrm{IFI}=.92, \mathrm{SRMR}=.07, \mathrm{AIC}=740$ ).

Hypothesis 1 proposed that the age-inclusive HR practices would be positively associated with age-diversity climate. The structural model offers support for this assumption because the path between age-inclusive HR practices and age-diversity climate was found to be positive and significant $(\beta=.20, t=2.19, p<.05)$. 


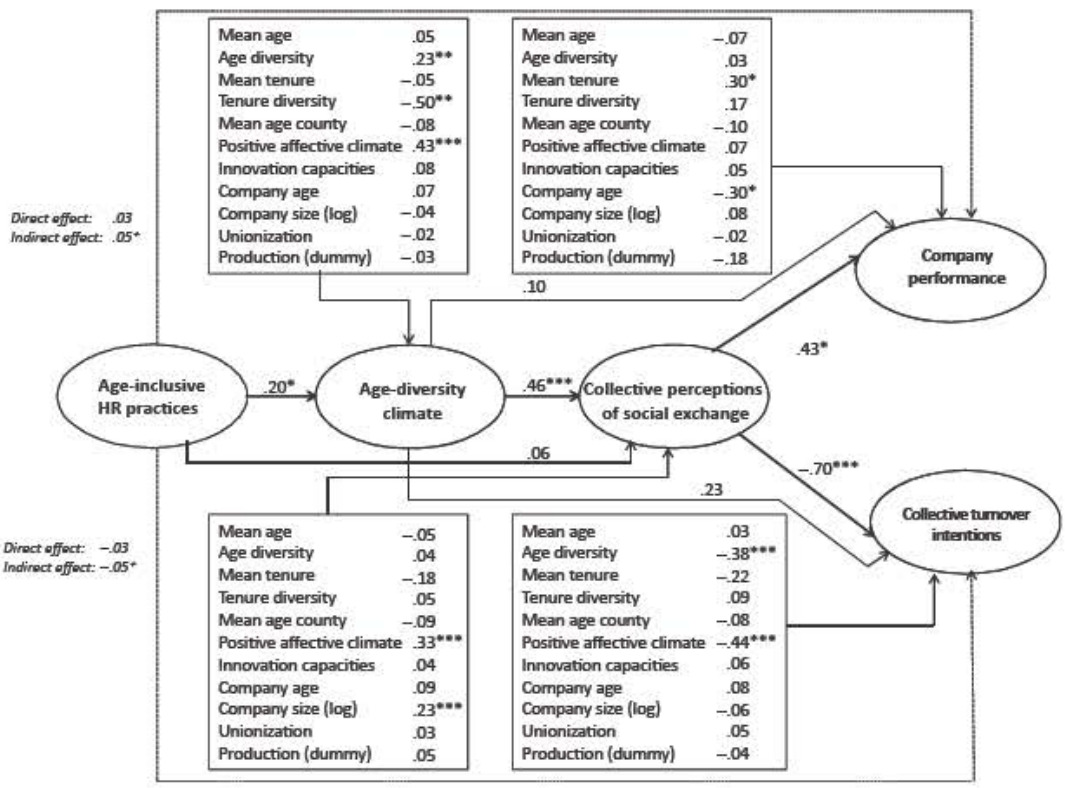

Figure 1: Structural Model Results.

Note. $N=93$. The indirect effects are based on 3,000 bootstrap estimates. Solid lines and dotted lines refer to direct and indirect relationships, respectively. ${ }^{* * *} p<.001$, two-tailed. ${ }^{* *} p<.01$, two-tailed. ${ }^{*} p<.05$, two-tailed.

Hypothesis 2 also received support from our analysis because, as expected, age-diversity climate was positively related to collective perceptions of social exchange $(\beta=.46, t=4.59, p<.001))^{4,5}$ Finally,

${ }^{4} \mathrm{As}$ the items for age-diversity climate and collective perceptions of social exchange were collected from the same employee dataset, there might be the risk for a same-source bias inflating this relationship (Podsakoff et al., 2012). For that reason, we specified an alternative model in which we allowed an intercorrelation of the error term of the two latent constructs. If high common method variance would be present, the directed relationship would vanish in such an error correlated model (Antonakis, Bendahan, Jacquart, \& Lalive, 2010). In order to identify this model we followed the advice by Shaver (2005) and used the control variables as instruments, which means that they were allowed to load on the age-diversity climate measure but not on the social exchange measure. In this alternative model the relationship between age-diversity climate and collective perceptions of social exchange remained significant on a $1 \%$ level, indicating a low probability for a common method bias driving our reported effects.

${ }^{5}$ To further validate the distinctiveness of the age-diversity climate and the collective perceptions of social exchange measures, we also ran a robustness check with a post hoc split sample design. For that purpose we randomly split the answers in each company in half, with $50 \%$ of the employees answering questions about age-diversity climate and another $50 \%$ of the employees answering questions about the collective perceptions of social exchange, which were then separately aggregated to the organizational level. In the 
Hypotheses 3 and 4 were both supported by our analysis, and as expected collective perceptions of social exchange were positively and significantly related to organizational performance $(\beta=.43, t=2.31, p<.05)$, whereas the linkage to collective turnover intentions was negative $(\beta=-.70, t=$ $-4.39, p<.001)$.

Because Hypotheses 1, 2, 3, and 4 received support from our analyses, we additionally investigated the extent to which age-inclusive HR practices were indirectly related to company performance and collective turnover intentions via the mediation of age-diversity climate and collective perceptions of social exchange. Our mediation hypotheses (Hypotheses 5 and 6) would be confirmed if the model fit did not improve and both indirect effects remained significant in the mediation model compared to the indirect-effects only model (Judge \& Colquitt, 2004). As can be seen in Table 2, the overall model fit of the hypothesized three-path mediation model is not significantly different from that of the indirecteffects only model (alternative model 1), which does not allow a direct relation between age-inclusive HR practices and the outcome measures. However, in line with our predictions, which assumed a purely indirect effect of age-inclusive HR practices mediated through age-diversity climate and collective perceptions of social exchange, the indirect-effects only model is more parsimonious. The analyses showed that the direct paths from age-inclusive HR practices to company performance ( $\beta=.03$, $t=.30, n s)$, from age-inclusive HR practices to collective turnover intentions $(\beta=-.03, t=-.31, n s)$, and the direct paths from age-diversity climate to company performance $(\beta=.10, t=.55, n s)$ and to collective turnover intentions $(\beta=.23, t=1.53, n s)$ were all nonsignificant in the mediation model, whereas the indirect relationships remained significant in the expected direction. These results point toward a full three-path mediation of the relationship between age-inclusive HR practices and company performance as well as collective turnover intentions, respectively, via age-diversity climate. To further validate the three-path mediation relationships, we applied bootstrapping procedures. As proposed by Cheung and Lau (2008), we used 3,000 bootstrapping samples. As shown in Figure 1, these analyses showed indirect significant effects from the age-inclusive HR practices to company performance $(\beta=-.05, z=1.67$, $p<.05)$ and collective turnover intentions $(\beta=.05, z=1.68, p<.05)$.

Furthermore, to inspect the robustness of our findings, we compared the three path mediation model to six alternative models. In detail, the

alternative model with the separated measures, again the relationship between age-diversity climate and collective perceptions of social exchange remained significant on a $1 \%$ level, further supporting our argumentation for the distinctiveness of the two constructs and the low probability of a common method bias. 
three-path mediation model compared favorably to (a) an only-direct effects model (alternative model 2) that only allowed the direct relationships between age-inclusive HR practices and company performance as well as collective turnover intentions, respectively, while all the indirect effects were set to zero; (b) a no-controls model (alternative model 3) in which all paths from the control variables to the dependent constructs were set to zero ${ }^{6}$; (c) a reversed-mediator model (alternative model 4 ) in which the order of the mediators age-diversity climate and collective perceptions of social exchange was reversed; and (d) a reversed-effect model (alternative model 5) that assumed a reversed direction for all hypothesized relationships. In addition, we tested (e) a mean age/age diversity moderation model (alternative model 6), which specified moderation terms of mean age as well as age diversity for both the age-inclusive HR practices/age-diversity climate path and the age-diversity climate/collective perceptions of social exchange path. This model also had an inferior fit and all moderation terms turned out to be nonsignificant, indicating that the tested relationships were not dependent of the age-structure of the companies. Finally, we also tested (f) an all-controls model (alternative model 7), which incorporated also the nonsignificant controls. In this model all hypothesized relationships remained significant on a 5\% level, further increasing our confidence in the results.

\section{Discussion}

This study investigated the emergence and effects of age-diversity climate at the organizational level of analysis. More specifically, we developed an integrated model attempting to specify how age-inclusive HR practices may impact employees' shared age-diversity climate perceptions, which in turn should be directly related to collective perceptions of social exchange and indirectly to both firm performance and collective turnover intentions.

Building upon existing work on diversity climate, we first developed a theoretical understanding and empirical measurement of a firm's agediversity climate. Next, we developed a measure of age-inclusive HR practices and drew from work of Kopelman et al. (1990) to explain how such organization-wide HR practices might positively influence members' age-diversity climate perceptions through processes of signaling and collective sensemaking (Hypothesis 1). Thirdly, building upon Cox's (1994) IMCD and social exchange theory, we linked age-diversity climate to collective perceptions of social exchange (Hypothesis 2), which in turn

\footnotetext{
${ }^{6}$ In this alternative model all proposed relationships remained significant on a $5 \%$ level.
} 
should predict firm performance (Hypothesis 3) and collective turnover intentions (Hypothesis 4). Finally, we argued for and tested two full mediation models of age-inclusive HR practices leading to firm performance (Hypothesis 5) and collective turnover intentions (Hypothesis 6) through their effects on age-diversity climate and collective perceptions of social exchange. In sum, we found support for all of our hypotheses.

We believe that these results contribute to the literature by substantiating and extending prior findings in at least four ways. First, with regard to the diversity climate literature, one important contribution of our study can be identified in terms of describing, validating, and empirically testing age-diversity climate as a special form of the more general diversity climate construct. This seems significant for at least two reasons. On the one hand, there is a clear research trend to describe more specified forms of climate (e.g., safety, justice, or cooperation climate) instead of general work climates as these allow for more detailed insights into climate-related forms of organizational behavior (Schneider et al., 2011). On the other hand, given the ongoing demographic change in most industrialized economies (Destatis, 2009; Tempest et al., 2002; U.S. Bureau of Labor Statistics, 2008), age diversity can be expected to become one of the most relevant diversity categories in the very near future. Moreover, as recent research shows, increasing levels of age diversity are far from having just a positive influence on employees' well-being and on firm performance (e.g. Kearney \& Gebert, 2009; Kunze et al., 2011, 2013; Zenger \& Lawrence, 1989). Consequently, both scholarly research on and the practical promotion and nurturing of a distinct age-diversity climate seem highly promising.

Our second contribution to the climate and HR literature concerns the analysis of age-inclusive HR practices as a distinct driver of heightened levels of age-diversity climate. Although scholars like Pugh et al. (2008) and Avery and McKay (2010) mention that HR practices were repeatedly proposed as potential sources of diversity climates, actual studies on this relation are scarce. Most empirical research deals instead with individual employees' demographic characteristics, such as their gender or ethnicity (e.g., Hicks-Clarke \& Iles, 2000; Kossek \& Zonia, 1993), or the demographic composition of the entire workforce (e.g., Kossek, Markel, \& McHugh, 2003; McKay \& Avery, 2006; Pugh et al., 2008) as drivers for organizational members' diversity climate perceptions. Our study differs significantly from this approach as it investigates the influence of actual HR practices on age-diversity climate. For practitioners, this might provide the advantage of having a toolkit on hand to help effectively manage an age-diverse workforce, as a supplement to focusing on recruiting issues (with which they can change only the demographic composition of their firm). In this regard, our study also contributes to the literature on 
age-related HR practices, which has mostly been descriptive to date and has focused more on the configuration and dissemination than on the performance consequences of such measures. In addition, existing scales seem to have been exclusively focused on the productive engagement of older employees. Although this is an important premise for the long-term engagement of an aging workforce, it might not be enough for the sustainable success of an age-diverse workforce. Therefore, we theoretically developed, empirically validated, and practically tested a new measure for an age-inclusive HR system. By providing empirical support for the hypothesis that age-inclusive HR bundles are relevant for performance and employee retention, this paper offers companies an even stronger motivation to actually install and foster such practices that enable an effective collaboration of both younger and older employees in the workplace. By doing so, we also followed a call by Lepak et al. (2006) and demonstrated that specific HR systems might indeed relate to specific organizational objectives, such as fostering positive diversity perceptions within firms.

Our third contribution to the climate literature relates to our two outcome variables: firm performance and collective turnover intentions. As described by McKay et al. (2009; Avery and McKay, 2010), there is a dearth of quantitative studies that investigate the organizational-level performance outcomes of diversity climate. Most of the existing studies have either established the consequences of diversity climate on the group or unit level. With our dataset that combines data from the corporate level of analysis (with regard to age-inclusive HR practices and performance of 93 independent companies) with aggregated data collected at the individual level of analysis (with regard to age-diversity climate and collective social exchange perceptions of 14,260 employees nested in these firms), we were able to test and affirm the positive relation between (age-)diverse work climates and firm performance as well as the negative relation to collective turnover intentions across companies, thereby supporting a "business case for diversity" (Robinson \& Dechant, 1997).

Our fourth and final contribution pertains to the linkage of the climate and the HR literature. Our study corroborated prior findings implying a mediating role of organizational climates in the HR practices-firm performance link (e.g., Bowen \& Ostroff, 2004; Chuang \& Liao, 2010; Takeuchi et al., 2007). We built upon and extended these findings by introducing age-diversity climate as a relevant mediator and thereby also better connected the strategic HR and the diversity literature. Indeed, supported by bootstrapping analyses, we even found a full mediation of age-diversity climate and collective perceptions of social exchange in the age-inclusive HR practices-firm performance relationship. We are, however, aware of the fact that there might be additional potential mediators of this relationship. As age-inclusive HR practices are developed to improve employees' 
skills, their motivation, and their opportunities to contribute, there might be further mediating processes that explain the underlying HR-performance relationship. For instance, investing in training and knowledge acquisition for employees of all age groups might help the employees to develop a better product innovation or customer service competency. Nevertheless, we believe that (age-)diversity climate is an especially powerful mediator as it reflects a workforce's potential to work together effectively and to include people irrespective of their demographic background-probably one of the most important triggers of long-term firm success.

\section{Practical Implications}

Most corporate leaders in industrialized countries seem to have realized that the demographic change with aging populations, low birth rates, and large cohorts of future retirees will have tremendous implications for their firms. HR managers, in particular, are increasingly aware of the fact that they bear an immense responsibility to manage the challenges of the ongoing demographic shift (e.g., lack of young professionals, aging of production staff, increasing age-diversity of the workforce) in order to secure the long-term productivity of their companies (Dychtwald et al., 2004; Elliott, 1995; Kunisch, Boehm, \& Boppel, 2011). Our study's results may support them in these endeavors.

First, practitioners should be aware of the fact that age-inclusive HR practices are a promising tool in managing an aging workforce. As our study has shown, potential elements of such age-inclusive HR bundles are age-neutral recruiting policies, equal access to training for all age groups, age-neutral career and promotion systems, initiatives to educate managers about leading age-diversity in the workplace, as well as the promotion of an age-inclusive corporate culture. Although these measures should not be regarded as an exhaustive list, they provide practitioners with a good starting point in order to effectively manage employees from all age groups. Moreover, as our analyses indicate, the introduction of such ageinclusive HR systems seems to be beneficial for all organizations and not just for those characterized by a high average age or a high age diversity of their workforce.

Second, HR managers as well as leadership personnel throughout the firm should be conscious of the crucial role of a positive age-diversity climate in translating (age-inclusive) HR measures into performance and employee retention. Consequently, the fostering of high levels of a proage-diverse climate seems very valuable. In addition to investing in HR practices that affect the age-diversity climate, companies could also think about influencing it in additional ways. In this regard, Pugh et al. (2008, 
p. 1427) have suggested "actively help[ing] their employees interpret what they see by pointing to the policies, practices, and procedures that contributed to creating and sustaining a diverse workforce." In other words, firms should not only install age-inclusive HR practices but also actively speak about them, increase their employees' awareness of them, and ultimately make these practices a key component of their so-called corporate DNA. By doing so, they should be able to promote even higher levels of age-diversity climate, which in turn should positively and sustainably impact their bottom line.

\section{Limitations and Future Research Directions}

Although this study profits from numerous methodological strengths (e.g., independent data sources for most study variables and a large organizational-level dataset), there are several limitations that should be noted when interpreting the study's findings.

First, this was a cross-sectional design study in nature, which prevents us from drawing final conclusions about causality. Although we hope to have provided convincing theoretical arguments for the described directions of influence, future studies should aim to overcome this limitation by applying a longitudinal research design. This seems especially relevant for study Hypothesis 1, which investigated the impact of ageinclusive HR practices on age-diversity climate. It might be particularly fruitful to study the introduction of age-inclusive HR practices at one point in time and to measure the development (and potential change) in members' age-diversity perceptions at later points in time. In addition, quasi-experimental research designs (Shadish, Cook, \& Campbell, 2002) in which participating organizations are randomly or post-hoc assigned to treatments (i.e., the introduction of age-inclusive HR practices) might allow a causal linkage to be established for the relationships observed in our study.

A second limitation of our study concerns the generalizability of its findings with regard to the cultural environment in which it was conducted. Although our sample comprises 93 organizations, they were all German small and medium-sized enterprises. As we know from existing research on topics related to the aging workforce (e.g., Chiu, Chan, Snape, \& Redman, 2001), the cultural background in which an organization is operating may influence the findings. Consequently, the specific German setting might have had an effect on the perception of age-diversity climate, for example. Future studies might, therefore, want to replicate our findings in other cultural settings, such as Asia or North America. Moreover, readers should keep in mind that our study only included small to medium-sized firms with no firm having more than 5,000 employees. To 
include companies above that size might further improve the generalizability of the present findings.

Third, our measure of organizational performance was obtained from key informants (i.e., the firms' executive board members) and a perceptual measure rather than a fully objective one. Although executive board members can be regarded as a good source of information on performance and the way to measure performance is a well-established one (Combs et al., 2005; Delaney \& Huselid, 1996; Kunze et al., 2011, 2013; Wall et al., 2004), researchers should strive to collect additional financial data, such as stock measures, to assess firm performance; however, due to the fact that most companies in our sample were privately owned, nonlisted firms, this was hardly possible for this study.

Beyond these limitations, our study offers several interesting directions for future research. First, future studies might be interested in proposing and testing additional mediators for the link between age-inclusive HR practices and organizational performance. Discrimination, for instance, might be a promising construct to examine because age-related discriminatory behavior can be regarded as a severe threat to organizational performance (Chiu et al., 2001; Duncan, Loretto, \& White, 2000; Hassell \& Perrewe, 1993, 1995; Kunze et al., 2011, 2013; Palmore, 1999; Snape \& Redman, 2003). The 22,857 charges of age discrimination filed in the United States in 2012 (U.S. Equal Employment Opportunity Commission, 2013) indicate the necessity for companies to consider how best to reduce any perceptions of age discrimination in the workplace. Age-inclusive HR practices and a positive age-diversity climate may be promising factors to reduce age discrimination and to foster cooperation and organizational performance (Boehm et al., in press).

Second, future research might consider additional antecedents and boundary conditions that foster and shape members' perceptions of agediversity climate and translate it into organizational performance and employee retention. For example, leadership behavior was proposed as an important determinant of diversity climate (Avery \& McKay, 2010), however, empirical work on this relationship is scarce. More specifically, transformational leadership might be an especially promising leadership style to foster perceptions of a pronounced age-diversity climate, given its generally positive effect in organizational settings characterized by high (age-)diversity (e.g., Kearney \& Gebert, 2009; Kunze \& Bruch, 2010; Shin \& Zhou, 2007). In addition, TMT attitudes, potential age stereotypes, as well as top-level leadership behavior might be important antecedents and moderators of the (age-)diversity climate-performance link (Gilbert \& Ivancevich, 2001; Wentling, 2004).

Third, scholars might find it worthwhile to build upon our findings and to develop multilevel models of the emergence and effects of age-diversity 
climate (see e.g., Gonzalez \& DeNisi, 2009). For example, it might be interesting to investigate how a distinct age-diversity climate at the organizational level of analysis translates into lower-level outcomes, such as cooperation or cohesion climate (on the group level of analysis) or individual job satisfaction or performance (on the individual level of analysis). In sum, we hope that this study contributes to a better understanding of the development and effects of age-diversity climate and provides a sound basis for future studies investigating this theoretically and practically relevant topic.

\section{REFERENCES}

Anderson JC, Gerbing DW. (1988). Structural equation modeling in practice: A review and recommended two-step approach. Psychological Bulletin, 103, 411-423.

Antonakis J, Bendahan S, Jacquart P, Lalive R. (2010). On making causal claims: A review and recommendations. The Leadership Quarterly, 21, 1086-1120.

Armstrong-Stassen M, Lee SH. (2009). The effect of relational age on older Canadian employees' perceptions of human resource practices and sense of worth to their organization. The International Journal of Human Resource Management, 20, 17531769.

Armstrong-Stassen M, Schlosser F. (2011). Perceived organizational membership and the retention of older workers. Journal of Organizational Behavior, 32, 319-344.

Armstrong-Stassen M, Templer A. (2006). The response of Canadian public and private sector human resource professionals to the challenges of the aging workforce. Public Personnel Management, 35, 247-260.

Arthur JB. (1994). Effects of human resource systems on manufacturing performance and turnover. Academy of Management Journal, 37, 670-687.

Aryee S, Budhwar PS, Chen ZX. (2002). Trust as a mediator of the relationship between organizational justice and work outcomes: Test of a social exchange model. Journal of Organizational Behavior, 23, 267-285.

Avery DR, McKay PF. (2010). Doing diversity right: An empirically based approach to effective diversity management. In Hodgkinson GP, Ford JK (Eds.), International review of industrial and organizational psychology (pp. 227-252). Indianapolis, IN: Wiley.

Batt R. (2002). Managing customer services: Human resource practices, quit rates, and sales growth. Academy of Management Journal, 45, 587-597.

Becker BE, Huselid MA. (1998). High performance work systems and firm performance: A synthesis of research and managerial implications. Research in Personnel and Human Resources Management, 16, 53-101.

Becker TE. (2005). Potential problems in the statistical control of variables in organizational research: A qualitative analysis with recommendations. Organizational Research Methods, 8, 274-289.

Bedeian AG. (2007). Even if the tower is "ivory," it isn't "white:" Understanding the consequences of faculty cynicism. The Academy of Management Learning and Education, 6, 9-32.

Blau P. (1964). Exchange and power in social life. New York, NY: Wiley.

Blau P. (1977). Inequality and heterogeneity. New York, NY: Free Press.

Bliese PD. (2000). Within-group agreement, non-independence, and reliability: Implications for data aggregation and analysis. In Klein KJ, Kozlowski SWJ (Eds.), 
Multilevel theory, research, and methods in organizations: Foundations, extensions, and new directions (pp. 349-381). San Francisco, CA: Jossey-Bass.

Boehm SA, Dwertmann DJG, Kunze F, Michaelis B, Parks KM, McDonald DP. (in press). Expanding insights on the diversity climate-performance link: The role of work group discrimination and group size. Human Resource Management.

Bowen DE, Ostroff C. (2004). Understanding HRM-firm performance linkages: The role of "strength" of the HRM system. Academy of Management Review, 29, 203-221.

Burke MJ, Dunlap WP. (2002). Estimating interrater agreement with the average deviation index: A user's guide. Organizational Research Methods, 5, 159-172.

Burke MJ, Finkelstein LM, Dusig MS. (1999). On average deviation indices for estimating interrater agreement. Organizational Research Methods, 2, 49-68.

Casper WJ, Harris CM. (2008). Work-life benefits and organizational attachment: Self interest utility and signalling theory models. Journal of Vocational Behavior, 72, 95-109.

Chen G, Mathieu JE, Bliese PD. (2004). A framework for conducting multilevel construct validation. In Yammarino FJ, Dansereau F (Eds.), Research in multilevel issues: Multilevel issues in organizational behavior and processes (Vol. 3, pp. 273-303). Oxford, UK: Elsevier.

Cheung GW, Lau RS. (2008). Testing mediation and suppression effects of latent variables: Bootstrapping with structural equation models. Organizational Research Methods, 11, 296-325.

Cheung GW, Rensvold RB. (2002). Evaluating goodness-of-fit indexes for testing measurement invariance. Structural Equation Modeling, 9, 233-255.

Chiu CK, Chan AW, Snape E, Redman T. (2001). Age stereotypes and discriminatory attitudes towards older workers: An East-West comparison. Human Relations, 54, $629-661$.

Choi YR, Shepherd DA. (2005). Stakeholder perceptions of age and other dimensions of newness. Journal of Management, 31, 573-596.

Chuang C-H, Liao H. (2010). Strategic human resource management in service context: Taking care of business by taking care of employees and customers. PERSONNEL PSYCHOLOGY, 63, 153-196.

Collins CJ, Smith KG. (2006). Knowledge exchange and combination: The role of human resource practices in the performance of high-technology firms. Academy of Management Journal, 49, 544-560.

Combs JG, Crook TR, Shook CL. (2005). The dimensionality of organizational performance and its implications for strategic management research. In Ketchen DJ, Bergh DD (Eds.), Research methodology in strategy and management (Vol. 2, pp. 259-286). Oxford, UK: Elsevier.

Combs JG, Liu Y, Hall A, Ketchen D. (2006). How much do high-performance work practices matter? A meta-analysis of their effects on organizational performance. Personnel Psychology, 59, 501-528.

Côté S, Morgan L. (2002). A longitudinal analysis of the association between emotion regulation, job satisfaction, and intentions to quit. Journal of Organizational Behavior, 23, 947-962.

Cox TH, Jr. (1994). Cultural diversity in organizations: Theory, research, \& practice. San Francisco, CA: Berrett-Koehler.

Craig LA, Paganelli V. (2000). Phased retirement: Reshaping the end of work. Compensation \& Benefits Management, 16, 1-9.

Cropanzano R, Mitchell MS. (2005). Social exchange theory: An interdisciplinary review. Journal of Management, 31, 874-900. 
Delaney JT, Huselid MA. (1996). The impact of human resource management practices on perceptions of organizational performance. Academy of Management Journal, 39, 949-969.

Delery JE, Shaw JD. (2001). The strategic management of people in work organizations: Review, synthesis, and extension. In Ferris G (Ed.), Research in personnel and human resource management (Vol. 20, pp. 165-197). Greenwich, CT: JAI Press.

Den Hartog DN, Boselie P, Paauwe J. (2004). Performance management: A model and research agenda. Applied Psychology: An International Review, 53, 556-569.

Destatis (Deutsches Statistisches Bundesamt). (2009). Bevölkerung Deutschlands bis 2060-12. Koordinierte Bevölkerungsvorausberechnung. Wiesbaden, Germany: Author.

Dickson MW, Resick CJ, Hanges PJ. (2006). Systematic variation in organizationallyshared cognitive prototypes of effective leadership based on organizational form. The Leadership Quarterly, 17, 487-505.

Duncan C, Loretto W, White PJ. (2000). Ageism, early exit, and British trade unions. Industrial Relations Journal, 31, 220-234.

Dychtwald K, Erickson T, Morison B. (2004). It's time to retire retirement. Harvard Business Review, 82, 48-57.

Eisenberger R, Hungtington R, Hutchison S, Sowa D. (1986). Perceived organizational support. Journal of Applied Psychology, 71, 500-507.

Elliott RH. (1995). Human resource management's role in the future aging of the workforce. Review of Public Personnel Administration, 15, 5-17.

Enders CK, Bandalos DL. (2001). The relative performance of full information maximum likelihood estimation for missing data in structural equation models. Structural Equation Modeling, 8, 430-457.

Felps W, Mitchell TR, Hekman DR, Lee TW, Holtom BC, Harman WS. (2009). Turnover contagion: How coworkers' job embeddedness and job search behaviors influence quitting. Academy of Management Journal, 52, 545-561.

Ferris GR, Arthur MM, Berkson HM, Kaplan DM, Harrell-Cook G, Frink DD. (1998). Toward a social context theory of the human resource management-organization effectiveness relationship. Human Resource Management Review, 8, 235-264.

Gardner TM, Wright PM, Moynihan LM. (2011). The impact of motivation, empowerment, and skill-enhancing practices on aggregate voluntary turnover: The mediating effect of collective affective commitment. PERSONNEL PSYCHOLOGY, 64, 315-350.

Gelade GA, Ivery M. (2003). The impact of human resource management and work climate on organizational performance. PERSONNEL PSYCHOLOGY, 56, 383-404.

Gelfand MJ, Nishii LH, Raver J, Schneider B. (2005). Discrimination in organizations: An organizational level systems perspective. In Dipboye R, Colella A (Eds.), Discrimination at work: The psychological and organizational bases (pp. 89-116). Mahwah, NJ: Erlbaum.

Gilbert JA, Ivancevich JM. (2001). Effects of diversity management on attachment. Journal of Social Psychology, 31, 1331-1349.

Gonzalez JA, DeNisi AS. (2009). Cross-level effects of demography and diversity climate on organizational attachment and firm effectiveness. Journal of Organizational Behavior, 30, 21-40.

Gouldner AW. (1960). The norm of reciprocity: A preliminary statement. American Sociological Review, 25, 161-178.

Harris KJ, Kacmar KM, Witt LA. (2005). An examination of the curvilinear relationship between leader-member exchange and intent to turnover. Journal of Organizational Behavior, 26, 363-378. 
Hassell BL, Perrewe PL. (1993). An examination of the relationship between older workers' perceptions of age discrimination and employee psychological states. Journal of Managerial Issues, 5, 109-120.

Hassell BL, Perrewe PL. (1995). An examination of beliefs about older workers: Do stereotypes still exist? Journal of Organizational Behavior, 16, 457-468.

Hicks-Clarke D, Iles P. (2000). Climate for diversity and its effects on career and organizational attitudes and perceptions. Personnel Review, 29, 324-345.

Hu L, Bentler PM. (1999). Cutoff criteria for fit indexes in covariance structure analysis: Conventional criteria versus new alternatives. Structural Equation Modeling, 6, $1-55$.

Huselid MA. (1995). The impact of human resource management practices on turnover, productivity, and corporate financial performance. Academy of Management Journal, 38, 635-672.

Judge TA, Colquitt JA. (2004). Organizational justice and stress: The mediating role of work-family conflict. Journal of Applied Psychology, 89, 395-403.

Kearney E, Gebert D. (2009). Managing diversity and enhancing team outcomes: The promise of transformational leadership. Journal of Applied Psychology, 94, $77-89$.

Konovsky MA, Pugh SD. (1994). Citizenship behavior and social exchange. Academy of Management Journal, 37, 656-669.

Kooij DTAM, Jansen PGW, Dikkers JSE, de Lange AH. (2010). The influence of age on the associations between HR practices and both affective commitment and job satisfaction: A meta-analysis. Journal of Organizational Behavior, 31, 11111136.

Kopelman RE, Brief AP, Guzzo RA. (1990). The role of climate and culture in productivity. In Schneider B (Ed.), Organizational climate and culture (pp. 282-318). San Francisco, CA: Jossey-Bass.

Kossek EE, Markel KS, McHugh PP. (2003). Increasing diversity as an HRM change strategy. Journal of Organizational Change Management, 16, 328-352.

Kossek EE, Zonia SC. (1993). Assessing diversity climate: A field study of reactions to employer efforts to promote diversity. Journal of Organizational Behavior, 14, $61-81$.

Kunisch S, Boehm SA, Boppel M (Eds.). (2011). From grey to silver-Managing the demographic change successfully. Heidelberg, Germany: Springer.

Kunze F, Boehm SA, Bruch H. (2011). Age diversity, age discrimination climate, and performance consequences-A cross-organizational study. Journal of Organizational Behavior, 32, 264-290.

Kunze F, Boehm SA, Bruch H. (2013). Organizational performance consequences of age diversity: Inspecting the role of diversity-friendly HR policies and top managers' negative age stereotypes. Journal of Management Studies, 50, 413-442.

Kunze F, Bruch H. (2010). Age-based faultlines and perceived productive energy: The moderation of transformational leadership. Small Group Research, 41, 593-620.

Lepak DP, Liao H, Chung Y, Harden EH. (2006). A conceptual review of human resource management systems in strategic human resource management research. In Martocchio JJ (Ed.), Research in personnel and human resources management (Vol. 25, pp. 217-271). Oxford, UK: Elsevier.

MacDuffie JP. (1995). Human resource bundles and manufacturing performance: Organizational logic and flexible production systems in the world auto industry. Industrial and Labor Relations Review, 48, 197-221. 
Masterson SS, Lewis K, Goldman BM, Taylor MS. (2000). Integrating justice and social exchange: The differing effects of fair procedures and treatment on work relationships. Academy of Management Journal, 43, 738-748.

McKay PF, Avery DR. (2006). What has race got to do with it? Unraveling the role of racioethnicity in job seekers' reactions to site visits. PERSONNEL PSYCHOLOGY, $59,395-429$.

McKay PF, Avery DR, Liao H, Morris MA. (2011). Does diversity climate lead to customer satisfaction? It depends on the service climate and business unit demography. Organization Science, 22, 788-803.

McKay PF, Avery DR, Morris MA. (2008). Mean racial-ethnic differences in employee sales performance: The moderating role of diversity climate. PERSONNEL PSYCHOLOGY, 61, 349-374.

McKay PF, Avery DR, Morris MA. (2009). A tale of two climates: Diversity climate from subordinates' and managers' perspectives and their role in store unit sales performance. PERSONNEL PSYCHOLOGY, 62, 767-791.

McKay PF, Avery DR, Tonidandel S, Morris MA, Hernandez M, Hebl MR. (2007). Racial differences in employee retention: Are diversity climate perceptions the key? PERSONNEL PSYCHOLOGY, 60, 35-62.

Moorman RH, Blakely GL, Niehoff BP. (1998). Does perceived organizational support mediate the relationship between procedural justice and organizational citizenship behavior? Academy of Management Journal, 41, 351-357.

Mor Barak ME, Cherin DA, Berkman S. (1998). Organizational and personal dimensions in diversity climate: Ethnic and gender differences in employee perceptions. Journal of Applied Behavioral Science, 34, 82-104.

Ostroff C, Bowen DE. (2000). Moving HR to a higher level: Human resource practices and organizational effectiveness. In Klein KJ, Kozlowski SWJ (Eds.), Multilevel theory, research, and methods in organizations (pp. 211-266). San Francisco, CA: Jossey-Bass.

Palmore EB. (1999). Ageism: Negative and positive (2nd ed.). New York, NY: Springer.

Patrickson M, Hartmann L. (1995). Australia's ageing population: Implications for human resource management. International Journal of Manpower, 16, 34-46.

Pierce JL, Gardner DG. (2004). Self-esteem within the work and organizational context: A review of the organization-based self-esteem literature. Journal of Management, 30, 591-622.

Podsakoff PM, Ahearne M, MacKenzie SB. (1997). Organizational citizenship behavior andthe quantity and quality of work group performance. Journal of Applied Psychology, 82, 262-270.

Podsakoff PM, MacKenzie SB, Podsakoff NP. (2012). Sources/causes of common method bias in social science research and recommendations on how to control it. Annual Review of Psychology, 63, 539-569.

Pugh SD, Dietz J, Brief AP, Wiley JW. (2008). Looking inside and out: The impact of employee and community demographic composition on organizational diversity climate. Journal of Applied Psychology, 93, 1422-1428.

Ragins BR, Cotton JL, Miller JS. (2000). Marginal mentoring: The effects of type of mentor, quality of relationship, and program design on work and career attitudes. Academy of Management Journal, 43, 1177-1194.

Ragins BR, Gonzalez JA, Ehrhardt K, Singh R. (2012). Crossing the threshold: The spillover of community racial diversity and diversity climate to the workplace. PERSONNEL PSYCHOLOGY, 65, 755-787.

Reichers AE, Schneider B. (1990). Climate and culture: An evolution of constructs. In Schneider B (Ed.), Organizational climate and culture (pp. 5-39). San Francisco, CA: Jossey-Bass. 
Robinson G, Dechant K. (1997). Building a business case for diversity. Academy of Management Executive, 11, 21-31.

Rogers EW, Wright PM. (1998). Measuring organizational performance in strategic human resource management: Problems, prospects and performance information markets. Human Resource Management Review, 8, 311-331.

Rowe WG, Morrow JL. (1999). A note on the dimensionality of the firm financial performance construct using accounting, market and subjective measures. Canadian Journal of Administrative Science, 16, 58-70.

Saba T, Guérin G, Wils T. (1998). Managing older professionals in public agencies in Quebec. Public Productivity \& Management Review, 22, 15-34.

Schneider B. (1990). The climate for service: An application of the climate construct. In Schneider B (Ed.), Organizational climate and culture (pp. 383-412). San Francisco, CA: Jossey-Bass.

Schneider B. (2000). The psychological life of organizations. In Ashkanasy NM, Wilderom CPM, Peterson MF (Eds.), Handbook of organizational culture and climate (pp. xvii-xxii). Thousand Oaks, CA: Sage.

Schneider B, Ehrhart MG, Macey WH. (2011). Perspectives on organizational climate and culture. In Zedeck S (Ed.), Handbook of industrial and organizational psychology (pp. 373-414). Washington, DC: American Psychological Association Press.

Schneider B, Reichers AE. (1983). On the etiology of climates. PERSOnNel PSYCHOLOGY, 36, 19-39.

Shadish WR, Cook TD, Campbell DT. (2002). Experimental and quasi-experimental designs for generalized causal inference. Boston, MA: Houghton Mifflin.

Shaver JM. (2005). Testing for mediating variables in management research: Concerns, implications, and alternative strategies. Journal of Management, 31, 330-353.

Shin SJ, Zhou J. (2007). When is educational specialization heterogeneity related to creativity in research and development teams? Transformational leadership as a moderator. Journal of Applied Psychology, 92, 1709-1721.

Shore LM, Randel AE, Chung BE, Dean MA, Ehrhart KH, Sing G. (2011). Inclusion and diversity in work groups: A review and model for future research. Journal of Management, 37, 1262-1289.

Shore LM, Tetrick LE, Lynch P, Barksdale K. (2006). Social and economic exchange: Construct development and validation. Journal of Applied Social Psychology, 36, $837-867$.

Shore LM, Wayne SJ. (1993). Commitment and employee behavior: Comparison of affective commitment and continuance commitment with perceived organizational support. Journal of Applied Psychology, 78, 774-780.

Sine WD, Mitsuhashi H, Kirsch DA. (2006). Revisiting burns and stalker: Formal structure and new venture performance in emerging economic sectors. Academy of Management Journal, 49, 121-132.

Snape E, Redman T. (2003). Too old or too young? The impact of perceived age discrimination. Human Resource Management Journal, 13, 78-89.

Spector P, Dwyer D, Jex S. (1988). Relation of job stressors to affective, health, and performance outcomes: A comparison of multiple data sources. Journal of Applied Psychology, 73, 11-19.

Takeuchi R, Lepak DP, Wang H, Takeuchi K. (2007). An empirical examination of the mechanisms mediating between high-performance work systems and the performance of Japanese organizations. Journal of Applied Psychology, 92, 10691083.

Taylor AB, MacKinnon DP, Tein JY. (2008). Tests of the three-path mediated effect. Organizational Research Methods, 11, 241-269. 
Tempest S, Barnatt C, Coupland C. (2002). Grey advantage-New strategies for the old. Long Range Planning, 35, 475-492.

Tsui AS, Pearce JL, Porter LW, Tripoli AM. (1997). Alternative approaches to the employee-organization relationship: Does investment in employees pay off? Academy of Management Journal, 40, 1089-1121.

U.S. Bureau of Labor Statistics. (2008). Older workers. Retrieved from http://www. bls.gov/spotlight/2008/older_workers/.

U.S. Equal Employment Opportunity Commission. (2013). Age discrimination. Retrieved from http://www.eeoc.gov/eeoc/statistics/enforcement/charges.cfm.

Van Katwyk PT, Fox S, Spector PE, Kelloway EK. (2000). Using the Job-Related Affective Well-Being Scale (JAWS) to investigate affective responses to work stressors. Journal of Occupational Health Psychology, 5, 219-230.

Van Knippenberg DL, Schippers MC. (2007). Work group diversity. Annual Review of Psychology, 58, 515-541.

Wall TD, Michie J, Patterson M, Wood SJ, Sheehan M, Clegg CW, West M. (2004). On the validity of subjective measures of company performance. PERSONNEL PSYCHOLOGY, 57, 95-118.

Wayne SJ, Shore LM, Bommer WH, Tetrick LE. (2002). The role of fair treatment and rewards in perceptions of organizational support and leader-member exchange. Journal of Applied Psychology, 87, 590-598.

Wentling RM. (2004). Factors that assist and barriers that hinder the success of diversity initiatives in multinational corporations. Human Resources Development International, 7, 165-180.

Zacharatos A, Barling J, Iverson RD. (2005). High-performance work systems and occupational safety. Journal of Applied Psychology, 90, 77-93.

Zenger TR, Lawrence BS. (1989). Organizational demography: The differential effects of age and tenure distributions on technical communication. Academy of Management Journal, 32, 353-376.

Zohar D. (2000). A group-level model of safety climate: Testing the effect of group climate on microaccidents in manufacturing jobs. Journal of Applied Psychology, 85, 587-596.

\section{APPENDIX}

Age-Inclusive HR-Practices

$(1=$ very low intensity; $5=$ very high intensity $)$

With how much intensity does your company ...

1. offer age-neutral recruiting activities?

2. offer equal access to training and further education for all age groups?

3. offer equal opportunities to be promoted, transferred, and to make further career steps irrespective of one's age?

4. offer training and education for managers on how to deal with an age-diverse workforce and how to respond to the needs of different age groups?

5. foster the promotion of an age-friendly organizational culture? 


\section{Age-Diversity Climate}

$(1=$ strongly disagree $; 7=$ strongly agree $)$

1. Our company makes it easy for people from diverse age groups to fit in and be accepted.

2. Where I work, employees are developed and advanced without regard to the age of the individual.

3. Managers in our company demonstrate through their actions that they want to hire and retain an age-diverse workforce.

4. I feel that my immediate manager/supervisor does a good job of managing people with diverse backgrounds (in terms of age).

(based on Pugh SD, Dietz J, Brief AP, Wiley JW. [2008]. Looking inside and out: The impact of employee and community demographic composition on organizational diversity climate. Journal of Applied Psychology, 93, 1422-1428).

\section{Collective Perceptions of Social Exchange}

$(1=$ strongly disagree $; 5$ = strongly agree $)$

1. The relationship between employees and our company continues to evolve and develop.

2. Employees in our company have significant opportunities to take on assignments that enhance their value.

3. Employees in our company don't mind working hard today - they know they will eventually be rewarded by our company.

4. Employees in our company try to look out for the best interest of the company because they can rely on the company to take care of them.

(based on Takeuchi R, Lepak DP, Wang H, Takeuchi, K. [2007]. An empirical examination of the mechanisms mediating between high-performance work systems and the performance of Japanese organizations. Journal of Applied Psychology, 92, 1069-1083).

\section{Company Performance}

\section{$(1=$ far below average; $7=$ far above average $)$}

Please assess the performance of your company compared to your main competitors in the same industry since the beginning of this year on the following dimensions:

Organizational performance

1. Company growth

2. Financial performance 
3. Return on assets

Operational performance

1. Employee productivity

2. Efficiency of business procedures

(based on Kunze F, Boehm SA, Bruch, H. [2011]. Age diversity, age discrimination climate, and performance consequences-A crossorganizational study. Journal of Organizational Behavior, 32, 264-290).

\section{Collective Turnover Intentions}

$(1=$ never $; 5=$ extremely often/always $)$

How often have you seriously considered quitting your job in the last 6 months? (based on Côté S, Morgan L. [2002]. A longitudinal analysis of the association between emotion regulation, job satisfaction, and intentions to quit. Journal of Organizational Behavior, 23, 947-962). 